\title{
ANÁLISE DA APROPRIAÇÃO DO CONCEITO DE VOLUME SOB A PERSPECTIVA DA TEORIA DA ATIVIDADE
}

\section{Analysis of the appropriation of the concept of volume by Activity Theory}

\author{
Vera Lúcia Gouvêa de Camargo Rodrigues ${ }^{1}$ \\ Marta Sueli de Faria Sforni ${ }^{2}$
}

\begin{abstract}
Resumo: De acordo com a Abordagem Histórico-Cultural e a Teoria da Atividade de Leontiev, apropriação de conceitos e desenvolvimento psíquico dos sujeitos são processos interligados. Com a intenção de compreendermos essa relação, desenvolvemos atividades orientadoras de ensino em uma $3^{\mathrm{a}}$ série do Ensino Fundamental, trabalhando com o conceito de volume para investigar o processo de apropriação conceitual pelos alunos. Observamos que as ações das crianças são reveladoras do seu desenvolvimento psíquico, à medida que evidenciam a utilização dos conceitos geométricos como instrumentos orientadores na busca de soluções diante de situações desafiadoras. A apropriação se revela na mudança da relação do sujeito com o objeto, ou seja, quando ele deixa de agir por tentativa e erro ou repetição mecânica de procedimentos e age mediante reflexão e análise, o que exige mobilização de funções psíquicas superiores.
\end{abstract}

Palavras-chave: Teoria da Atividade. Conceitos científicos. Volume. Aprendizagem. Atividade de ensino.

\begin{abstract}
According to the Historical and Cultural Approach and Leontiev's Activity Theory, the subjects' appropriation of concepts and psychic development are interlinked processes. Monitored learning activities on the concept of volume have been developed in a $3^{\text {rd }}$ year primary school class to investigate the students' conceptual process. Children's activities revealed their psychic development as they used geometrical concepts such as monitoring instruments for the solution of challenging situations. Appropriation is revealed when there is a change in the relationship between subject and object, or rather, when the subject quits activities by trial and error or the mechanical repetition of procedures and acts according to reflection and analysis. The latter requires the mobilization of higher psychic functions.
\end{abstract}

Keywords: Activity Theory. Scientific concepts. Volume. Learning. Teaching activities.

\footnotetext{
${ }^{1}$ Licenciada em Matemática e Ciências, mestre em Educação. Docente, Faculdade Metropolitana de Maringá. Maringá, PR, Brasil. <veraluciarodrigues@yahoo.com.br>

${ }^{2}$ Licenciada em Pedagogia, doutora em Educação. Docente, Programa de Pós-Graduação em Educação, Universidade Estadual de Maringá. Maringá, PR, Brasil. <martasforni@uol.com.br>
}

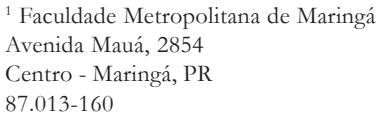




\section{Introdução}

Com a intenção de analisarmos elementos reveladores da relação entre desenvolvimento psíquico e apropriação conceitual, organizamos situações orientadoras de ensino e elegemos, como conteúdo da intervenção, o conceito de volume. Nessa investigação, nos foi possível analisar, em situações de ensino ocorridas em sala de aula, as diferentes relações dos estudantes com o objeto de conhecimento, identificando sinais que evidenciam a relação entre ações mentais e a ocorrência de apropriação dos conceitos.

A preocupação com o processo de ensino de Matemática decorre dos problemas que envolvem a sua aprendizagem. Apesar de a Matemática ser uma disciplina presente na educação escolar desde as séries iniciais, pesquisas têm demonstrado que a aprendizagem dos conteúdos dessa área de conhecimento constitui um obstáculo para grande número de estudantes. Os altos índices de evasão e repetência, bem como os resultados de processos avaliativos governamentais denunciam que, tanto nas escolas públicas como nas particulares, os alunos não têm se apropriado adequadamente desse conteúdo. Dessa forma, a Matemática constitui mais uma das disciplinas que contribuem para o fracasso escolar.

A constatação mencionada pode ser verificada mediante os resultados das avaliações sobre o desempenho escolar levadas a termo pelo Ministério da Educação e Cultura (BRASIL, 2010), efetuadas pelo Sistema Nacional de Avaliação da Educação Básica (SAEB). No Exame Nacional do Ensino Médio (ENEM) de 2009, dentre as quatro áreas avaliadas - matemática, ciências humanas, ciências da natureza e linguagens - na área de matemática, os alunos tiveram o pior desempenho. Mais da metade dos participantes - 57,7\% - ficaram abaixo da média (BRASIL, 2009a). No que se refere ao desempenho dos estudantes das séries/anos iniciais do Ensino Fundamental, avaliado por meio da Prova Brasil, observa-se que houve melhora em 2009. Em 2007, a pontuação alcançada foi 193,5 e, em 2009, esse índice subiu para 204,3. Todavia, os alunos ainda não atingiram o nível mínimo esperado para os concluintes dessas séries, que é de 225 pontos (BRASIL, 2009b, 2007).

Os resultados dessas avaliações acabam reforçando resultados já revelados por pesquisadores em educação matemática, que há muito denunciam os problemas inerentes ao ensino e à aprendizagem do conhecimento matemático. Fiorentini e Miorim (1993) mostram que os alunos não compreendem a Matemática que é ensinada na escola e não sabem utilizála no seu cotidiano.

Essa situação é acentuada quando se avalia o ensino e a aprendizagem de contéudos geométricos, como aponta Pavanello (1989) - a Geometria ainda está bastante ausente das salas de aula, sobretudo na Educação Infantil e séries iniciais do Ensino Fundamental. Este pensamento é corroborado por Lorenzato (1995, p. 4), que considera que a ausência da Geometria na educação escolar está relacionada ao despreparo do professor: “[...] como ninguém pode ensinar bem aquilo que não conhece, está aí mais uma razão para o atual esquecimento geométrico."

No cotidiano escolar, normalmente, educadores e estudantes ficam presos às finalidades imediatas do ensino. Considera-se que o estudante deve aprender determinados conteúdos porque serão objetos de avaliação na própria escola, nas avaliações externas, no vestibular ou em concursos e seleções para empregos. A reflexão sobre a situação da aprendizagem do conteúdo matemático na escola pode nos levar à crença de que, se mais tempo fosse dedicado 
ao ensino dessa ciência, se houvesse maior empenho por parte dos professores ou, ainda, se as escolas dispusessem de mais materiais didáticos concretos, esses problemas seriam resolvidos. Tanto a preocupação exclusiva com demanda imediata do ensino, como as soluções apontadas para a melhoria do rendimento escolar, não tocam na essência do conteúdo ensinado. Essas discussões, ao naturalizarem os conteúdos, acabam por nos distanciar da preocupação com o conteúdo escolar, como instrumento cognitivo no sentido apontado pela abordagem Histórico-Cultural e pela Teoria da Atividade de Leontiev. É necessário, portanto, avaliar como organizar práticas pedagógicas que tenham, como meta, a aprendizagem de conceitos matemáticos como instrumentos cognitivos, para que os estudantes possam desenvolver modos de pensar e atuar próprios dessa área do conhecimento.

\section{Fundamentação teórica}

Davydov (1988), fundamentando-se no materialismo histórico, portanto, compreendendo o desenvolvimento humano como algo promovido socialmente, nos conduz à mudança de foco: da atenção sobre questões periféricas do ensino para análise do próprio conteúdo da aprendizagem e na atividade intelectual do sujeito no processo de apropriação desse conteúdo. Considerando-se que à escola não cabe a tarefa de ensinar uma grande soma de conhecimentos, mas desenvolver, nos alunos, as condições para que possam interagir com as informações científicas ou qualquer outro tipo de conhecimento, Davydov enfatiza que a escola deve ensinar os estudantes a pensarem e, para isso, deve desenvolver, ativamente, os fundamentos do "pensamento contemporâneo", caracterizado pelo elevado nível de abstração que é próprio dos conhecimentos teórico-científicos. Para ele, em razão do alto nível de desenvolvimento científico e tecnológico que alcançou a sociedade, somente o pensamento que consegue analisar, refletir e planejar é que estaria em condições de interagir com a sociedade nos tempos atuais. Davydov denomina, esse nível de pensamento, de pensamento teórico.

Libâneo (2010) afirma que, para Davydov, a atividade de aprendizagem está assentada no conhecimento teórico-científico, ou seja, no desenvolvimento do pensamento teórico e nas ações mentais que lhe correspondem.

O ensino propicia a apropriação da cultura e desenvolvimento do pensamento. São dois processos articulados entre si, formando uma unidade. Podemos expressar essa idéia de duas maneiras:

- à medida que o aluno forma conceitos científicos, incorpora processos de pensamento e vice-versa.

- enquanto forma o pensamento teórico-científico, o aluno desenvolve ações mentais mediante a solução de problemas que suscitam a atividade mental do aluno. Com isso, o aluno assimila o conhecimento teórico e as capacidades e habilidades relacionadas a esse conhecimento. Sendo assim, o papel da escola é ajudar os alunos a desenvolver suas capacidades mentais, ao mesmo tempo em que se apropriam dos conteúdos. (LIBANEO, 2010, p. 7) 
Apesar de muitas propostas curriculares reconhecerem que o ensino de Matemática possibilita o desenvolvimento psíquico do sujeito em toda a sua dimensão, encontramos, na grande maioria das escolas, uma aprendizagem direcionada à manipulação algorítmica e ao estudo das regras operacionais, contemplando a transmissão mecânica do conhecimento. No tocante à Geometria, nas séries iniciais, não é raro que o ensino limite-se a atividades que conduzam à identificação e à diferenciação das figuras e sólidos geométricos, exigindo do aluno apenas o domínio da palavra-termo que correponde a cada uma das figuras ou sólidos apresentados. Dessa forma, mobilizam-se, no aluno, apenas capacidades, como atenção, percepção e memória, que são capacidades necessárias, porém não suficientes para o desenvolvimento do pensamento teórico.

Nas sociedades em que a cultura está sistematizada e não diretamente acessível, cabe à educação escolar um papel significativo na aquisição de instrumentos cognitivos que permitam ao homem adquirir e participar desse universo cultural. Dada a complexidade dos instrumentos e signos presentes no contexto social em que vivemos, maior é a necessidade de a escola ser o local responsável por essa formação. O desenvolvimento do pensamento é um dos fatores mais importantes da aprendizagem escolar, entretanto, por sabermos que não é qualquer ensino que proporciona tal desenvolvimento, cabe-nos buscar elementos que nos ajudem a identificá-lo.

Quando se procura entender o desenvolvimento da criança na escola é preciso compreender como ocorre o desenvolvimento mental em razão da aprendizagem. Dois aspectos merecem atenção neste estudo do desenvolvimento do pensamento, "as mudanças da estrutura do próprio significado da palavra e estudar as funções, os modos de movimento das palavras que podem realizar-se no pensamento discursivo", como indica Vygotsky (2001, p. 522).

O desenvolvimento do processo de conceitualização acontece no processo de apropriação dos conhecimentos historicamente elaborados e acumulados pela humanidade, mediado pela prática-social, pela palavra, na interação com os outros. A palavra, em sua gênese, constitui uma forma primária do conceito, na medida em que reproduz uma generalização da realidade.

Entretanto, quando a palavra começa a ser utilizada, o seu desenvolvimento, no pensamento da criança, vai sofrendo profundas mudanças, evidenciando que os significados das palavras se modificam. O conceito, representação do real, depende das interações sociais de que a criança participar. Leontiev (1998), quando analisa o desenvolvimento da psique infantil, considera que o lugar que a criança ocupa no sistema de relações humanas se altera, em decorrência da influência das circunstâncias concretas da vida. A criança não é passiva diante desse contexto, mas age com e sobre ele. "Existem momentos em que determinado tipo de atividade é mais significativo que outros na relação da criança com a realidade" (SFORNI, 2004, p. 91). Leontiev (1998) denomina esse tipo de atividade, que caracteriza diferentes etapas do desenvolvimento, de atividade dominante ou principal.

Leontiev (1998) mostra os processos de desenvolvimento psíquico em duas situações: uma mais ampla, quando o condiciona à mudança da atividade dominante; e outra, quando se refere às mudanças no interior da própria atividade, sobretudo o surgimento das ações e a transformação dessas em operações. Quando as ações tornam-se procedimentos para alcançar um objetivo, configuram-se como operações. Entendemos que esta última situação contempla momentos mais pontuais do desenvolvimento que podem ser verificados no interior da atividade de estudo, que são importantes para o propósito desta pesquisa. 
Análise da apropriação do conceito ...

Para Leontiev (1998), sistematizador da Teoria da Atividade, a estrutura da atividade é constituída pelas necessidades, motivos, finalidades e condições de realização da atividade. A necessidade é um fator gerador condicionante de uma atividade. Ela motiva a criança a ter objetivos e, para que esses objetivos sejam atingidos, são necessárias ações físicas e mentais.

A Geometria, definida por Lima e Moisés (1998, p. 2), “[...] é a matematização do espaço em todas as suas dimensões. É a linguagem criada para apreensão humana dos movimentos das formas, de suas variações e transformações", uma área de conhecimento que pressupõe a ação do homem em medições e construções que, ao se constituírem para atender suas necessidades práticas, permitem ao homem a interpretação, o controle e a modificação do espaço, em que a medida de volume é um instrumento fundamental.

A linguagem matemática não deve ser utilizada apenas para explicar fenômenos da natureza, mas também para resolver problemas que, formulados na mente humana de forma totalmente abstrata, não são palpáveis. Isso não significa que o conceito de volume não tenha sido associado a necessidades naturais básicas do homem.

Pelo contrário, as motivações para a sua origem podem surgir de uma concepção espontânea, geralmente ligada à vivência sociocultural dos sujeitos. Por exemplo, quando nosso olhar é dirigido para questões como: Quanto de ar há naquela caixa? Quanto de soja pode ser armazenado naquele silo? Do ponto de vista do ensino, cabe-nos perguntar: Como responder a essas questões, sem nos deixarmos levar pelas impressões imediatas? Que elementos podem promover a consciência teórica do fenômeno, de tal forma que a criança tenha uma qualidade nova em suas futuras ações?

Embora se possa ter uma concepção espontânea de volume ao se lidar com problemas como os citados, a ideia de volume não é suficiente para resolvê-los. O sujeito não é capaz de formular conceitos científicos por simples observações de fenômenos naturais, se não puder contar com uma instrução culturalmente elaborada e, em geral, coordenada pela escola e orientada intencionalmente por um professor, para chegar à apropriação e generalização de tais conceitos.

Para desenvolver esse conhecimento nos alunos, é preciso que o conceito de volume esteja presente como um instrumento cultural, buscando a sua essência como produção humana e entendendo-o na interação do homem com o meio.

\section{Procedimentos metodológicos}

A pesquisa de campo foi desenvolvida em uma $3^{\text {a }}$ série do Ensino Fundamental, composta de 34 alunos e uma professora, em uma escola da rede Municipal, situada em bairro periférico da cidade de Maringá onde, como docente de Prática de Ensino, já desenvolvíamos um trabalho de dois anos com um grupo de professoras, alunas do curso de Pedagogia (RODRIGUES, 2006). A escolha da série justificou-se pelo fato de, apesar de constar no planejamento, o conteúdo de Geometria ainda não havia sido desenvolvido com as crianças, conforme afirmação da professora da sala.

Entendemos que o pesquisador, ao fazer parte deste cenário, assume ações participativas, "não apenas de observador do fenômeno ensino-aprendizagem, mas principalmente, podendo planejá-lo e com certeza interferindo na sua execução", como aponta Passos (2000, 
p. 122), colocando-se como elemento que potencializa a situação que está sendo estudada. Nesse sentido, a interação entre os sujeitos da pesquisa - pesquisador, professor e estudantes é muito importante para que se possa revelar a multiplicidade de dimensões presentes, levandose em conta que o cotidiano da sala de aula é influenciado pelas relações interpessoais e pelos acontecimentos do contexto sociocultural em que estão inseridos os sujeitos da pesquisa.

Embora, em alguns momentos, essas possíveis relações entre as situações e o contexto sociocultural terem sido apresentadas, o foco desta pesquisa esteve centrado nas situações de ensino, buscando os elementos que respondiam aos nossos propósitos.

O conceito de atividade na abordagem Histórico-Cultural e na Teoria da Atividade de Leontiev (1998) foi determinante da metodologia adotada na pesquisa de campo. Na identificação dos elementos de organização do pensamento presentes na aprendizagem da medida espacial de volume, tínhamos a intenção de observar, durante o desenvolvimento das situações de ensino, as ações e operações dos estudantes que, segundo a Teoria da Atividade, revelam o movimento do pensamento de uma qualidade à outra.

Nesse sentido, as atividades de ensino foram planejadas de forma que os alunos fossem estimulados a participar de situações compartilhadas, permitindo um acompanhamento maior da explicitação verbal de seu pensamento e das ações dele decorrentes durante a realização das atividades.

Essas atividades de ensino, planejadas e efetivadas em sala de aula, com a intervenção adulto-criança e criança-criança, foram denominadas de "atividades orientadoras". Moura (1992) utiliza esse termo para se referir a uma atividade intencionalmente organizada, capaz de desencadear um conjunto de ações que busca a resposta a uma situação de conflito que pode levar à aprendizagem do novo conceito. Para o autor, a atividade orientadora de ensino é:

[...] aquela que se estrutura de modo a permitir que sujeitos interajam, mediados por um conteúdo negociando significados, com o objetivo de solucionar coletivamente, uma situação problema. [...] a atividade orientadora de ensino tem uma necessidade: ensinar, tem ações: define o modo ou procedimentos de como colocar os conhecimentos em jogo no espaço educativo; e elege instrumentos auxiliares de ensino: os recursos metodológicos adequados a cada objetivo e ação (livro, giz, computador, ábaco, etc.). E, por fim, os processos de análise e síntese, ao longo da atividade, são momentos de avaliação para quem ensina e aprende. (MOURA, 2001, p. 155)

No interior da atividade orientadora, temos "episódios de ensino" denominados, por Moura (1992, p. 77), como "o conjunto de ações que desencadeia o processo de busca da resposta do problema em questão". O olhar atento para essas ações, buscando identificar de que forma a criança chegou a uma solução, é o que permite a compreensão da qualidade de sua aprendizagem. 


\section{Análise de um episódio de ensino}

Diante da grande quantidade de material coletado durante o desenvolvimento do projeto, tornou-se necessário selecionar, para fins de análise, atividades de ensino que nos permitissem atender aos objetivos da pesquisa. Para essa análise, selecionamos uma das atividades de ensino: Confeccionando a caixinha para o Jogo de Memória.

Em atividades anteriores, trabalhamos com os sólidos geométricos iniciando com interpelações. Que necessidades foram impostas ao homem para que cidades, como a nossa, fossem construídas? Que significa zona urbana? Essas questões desencadearam, nas crianças, ações que as levaram a construir uma maquete intitulada: $A$ Geometria na zona urbana. $\mathrm{Na}$ dinâmica da atividade, estabeleceram-se ações que conduziram à elaboração de novos conhecimentos, tais como: o sólido geométrico que representa o cubo, o paralelepípedo, o cone, os prismas, a esfera, etc., bem como, as faces, as arestas e os vértices presentes nesses sólidos geométricos.

Com o intuito de observar a utilização, pelos alunos, dos conceitos de figuras geométricas planas em outra situação, propusemos a construção do Jogo de Memória. Além do que, também, teríamos, nas trinta peças do jogo, as unidades de medida de volume necessárias ao desenvolvimento desse conceito. $\mathrm{O}$ jogo como estratégia de ensino deve cumprir o papel de auxiliar no ensino do conteúdo, propiciar a aquisição de modos de ação e permitir que o aluno aprofunde o que já foi estudado, mostrando que a matemática é um conjunto articulado de conceitos interdependentes.

Entregamos, para cada equipe, um envelope contendo: trinta peças quadradas de cinco centímetros de lado de material emborrachado tipo E.V.A.; 15 etiquetas com figuras geométricas planas e 15 etiquetas com o nome de cada uma das figuras utilizadas. Solicitamos que cada equipe colasse, em cada peça quadrada, as etiquetas recebidas, para a montagem de um Jogo de Memória.

Diante da dificuldade na identificação das figuras, a mediação da professora se fez presente, com questionamentos sobre o que estavam observando e sugerindo a consulta às anotações feitas no caderno em aulas anteriores.

$\mathrm{Na}$ construção do jogo, os alunos realizaram diversas ações que mobilizavam funções psíquicas superiores: a atenção era dirigida para os diferentes tipos de peças; a memória era ativada na busca de conteúdos e experiências vivenciadas anteriormente; a percepção voltavase para as formas da figura no momento em que comparavam e analisavam as propriedades geométricas das peças.

Ao jogar, quando os alunos não se utilizavam mais das anotações, demonstravam que já podiam fazer aquilo que só conseguiam, inicialmente, realizar com ajuda. A anotação era um signo externo, presente no caderno que, com a necessidade desencadeada pelo jogo, vai, aos poucos, tornando-se signo interno, mediador da memória. A mediação, para Vygotsky (1984), constitui um processo de intervenção de elementos sócio-históricos nas relações do homem com o mundo; o autor entende que essa relação não é direta, mas uma relação mediada por elementos como um instrumento, um signo. No caso específico, a atividade potencializou esse processo ao desencadear a necessidade de internalização do conteúdo trabalhado. Observamos que os sujeitos se colocam em atividade em função de uma necessidade desencadeada pela atividade proposta. 
De posse das peças do jogo, as unidades de medida que seriam utilizadas para o estudo de volume, apresentamos a seguinte situação para as crianças:

"- Logo, estaremos participando das atividades da Mostra de Trabalhos realizada anualmente na escola, oportunidade em que a comunidade vem conbecer um pouco do que vocês realizam aqui. Um dos trabalhos que poderemos mostrar é o Jogo de Memória das figuras geométricas. Precisamos construir uma caixinha bem bonita para guardar este jogo."

A intenção era colocar as crianças diante de duas situações: Como agrupar aquelas peças para ter a noção espacial deste volume? - e, por outro lado, a construção não poderia ser para qualquer caixa. Qual a caixa mais adequada para guardar essa quantidade de peças?

Essa atividade serviu de instrumento para a observação do movimento do pensamento dos alunos, evidenciado na linguagem e nas ações realizadas durante a montagem do sólido geométrico (a caixinha), com uma capacidade igual ao volume dado (total de peças do jogo).

Profi. W: - "Vamos organizar as equipes".

Pesq.: - "O grupo vai planejar como será esta caixinha, montar um mapa para a construção da caixinha e enviá-lo como sugestão para seus colegas. Mas a sugestão precisa ser bem detalhada para que os colegas da outra equipe possam compreender cada passo da construção da embalagem".

A Mostra de Trabalhos organizada pela escola foi uma situação propícia para a mobilização das ações dos alunos. O mapa, a planificação do sólido geométrico, foi uma forma de observar a sistematização e a comunicação dos dados remetidos para a outra equipe. O registro dessas ações por meio da linguagem escrita nos permitiu: compreender o raciocínio que os alunos estavam utilizando, as habilidades no manuseio de instrumentos de medida e hipóteses levantadas. Destacaremos, aqui, algumas das ações que entendemos terem sido importantes para nosso estudo.

A Profa ${ }^{a}$ W ajuda a distribuir os papéis nas equipes e as peças do Jogo de Memória de cada equipe.

$$
\begin{aligned}
& \text { Criança JU: - "Mas se a gente não conseguir montar a caixinha, professora?" } \\
& \text { Pesq.: - "Devolve para o grupo corrigir o que não deu certo." }
\end{aligned}
$$

\section{Episódio 01}

Uma equipe, formada por quatro crianças, começa a manipular as peças e consegue agrupá-las em três blocos, contendo dez peças cada um.

A criança LO: Olha para a pilha de peças e diz:

\section{- "Vai ter que ser retângular."}


Como retomar o conceito de paralelepípedo? Ao professor cabe estimular a correspondência com o real, para que ocorra a generalização, permitindo que a criança estabeleça relações entre a face retangular e o sólido geométrico (paralelepípedo).

$$
\begin{aligned}
& \text { Pesq.: - "Isto, como uma caixa de sapato." } \\
& \text { Criança LE: - "Professora, não dá para faz̧er uma caixa quadrada?" } \\
& \text { Criança LO: - "Não dá, são trinta peças." }
\end{aligned}
$$

A criança LE olha, coloca a mão na cabeça, demonstrando que não se convenceu.

A criança LO fica em dúvida, falou sobre a impossibilidade de montar uma caixa quadrada, mas não sabe explicar por que esse formato não seria adequado para armazenar as trinta peças. Desmancha a pilha feita dizendo:

$$
\text { - "Dá para colocar dez embaixo, dez em cima e mais dez, quer ver?” }
$$

A criança LE conta as peças e vai separando de dez em dez. As duas tentam formar um quadrado e não conseguem, enquanto isso, as outras duas crianças ficam observando.

Criança LO: - "vamos faz̧er como estava, não dá, está muito difícil, a gente ainda tem que fazer uma carta."

\section{Episódio 02}

Em outra equipe, ao repartirem as peças entre si, as crianças percebem que sobram peças e que, portanto, alguma coisa não estava certa.

A criança MT pega as peças de todos e fala:

\section{- "Tem que fazer tudo junto, é uma caixa para tudo."}

Todos começam a juntar as peças, comparando a altura das pilhas e, depois, contam quantas peças há em cada uma delas, formando três blocos com dez peças em cada um. Daí em diante, começam a elaborar o mapa da caixinha.

A criança CA pega a sua folha, coloca as peças em cima dela e vai circulando-as, para obter o fundo da caixa.

Já a criança BR utiliza a régua para medir o comprimento, a largura e a altura, e vai transcrevendo para sua folha, na construção do mapa da caixinha.

Nesse episódio, vale ressaltar o momento em que a criança LO olha para a pilha e afirma que a caixa precisa ser retangular; e quando a criança LE, ao se defrontar com a organização inicial que seu grupo tinha dado às peças do jogo, questiona sobre a possibilidade de outra forma para a caixinha, se a forma da caixa poderia ser quadrada. O conflito gerado faz com que desmanchem a pilha já montada e tentem distribuir as peças de forma que as camadas formassem quadrados. Vale lembrar que o jogo era composto por trinta peças. 
Percebemos que, enquanto as ações das crianças eram dirigidas para o objeto representado pela caixa, o conceito de sólido geométrico (paralelepípedo), traduzido pela linguagem verbal, era outro, pois se referiam à caixa como se ela fosse um retângulo. Ambos se referiam ao sólido geométrico, a caixa, como uma de suas faces. Conceitos espontâneos envolvendo esses termos fazem parte do cotidiano dessas crianças. Para a compreensão da essência do conceito não bastam definições, é preciso que a atividade desencadeie necessidades de mobilização de suas ações. Observamos que o processo de medida de volume possibilita conhecimentos novos para algumas crianças, desenvolvendo a atenção, a capacidade de planejar, analisar e generalizar - isso ocorre quando a atividade desperta questionamentos, como os da criança LE.

Os conteúdos escolares, se devidamente organizados e mediados pelo professor, quando colocados como instrumentos na aprendizagem da criança, possibilitam que ela atinja um nível mais elevado em seus conceitos espontâneos, de tal forma que tornem possível o surgimento dos conceitos científicos (SFORNI, 2004).

$\mathrm{Na}$ elaboração do mapa da caixa, a criança BR utilizava instrumento de medida, enquanto a criança CA circulava as peças, sem a preocupação com as medidas. Constatamos que a última era uma ação manifestada pela maioria das crianças. Nas planificações, observamos a preocupação com a quantidade de faces necessárias; suas formas geométricas e medidas, apesar de não demonstrarem habilidades no uso de instrumentos de medida.

Diante das dificuldades apresentadas pelas crianças, tanto na planificação como na escrita de sugestões para a construção da caixinha, sentimos a necessidade de redimensionarmos nossas ações de ensino. Cabe destacar que essa é mais uma das características da atividade orientadora de ensino. Diferentemente de um planejamento rígido, que estabelece, a priori, o que deve ser cumprido, o planejamento da atividade orientadora é mais flexível, tendo como preocupação a aprendizagem dos alunos, possibilitando a modificação da mesma ao longo do processo, se o professor julgar necessário ao avaliar suas ações frente à aprendizagem que está se processando. Mantém-se a intencionalidade, mas sem a rigidez das atividades previstas. É nesse sentido que a atividade orientadora de ensino também é um instrumento de aprendizagem para o professor, pois o coloca em constante movimento de reflexão sobre os processos de ensino e aprendizagem. Optamos pela estruturação de um texto para dirigirmos a atenção dos alunos a aspectos que deveriam levar em consideração para a construção do sólido geométrico em função do volume dado.

Levantamos com as crianças os elementos essenciais: a forma das peças do Jogo; o número total de peças; o número de peças que seriam colocadas em cada camada; o número de camadas possíveis; a forma da caixa mais adequada para um maior aproveitamento do papel que iríamos utilizar; suas medidas e os instrumentos necessários para desenvolver esta ação. A prof'. W produziu, juntamente com as crianças, o texto coletivo intitulado: "A construção da caixa".

Esse procedimento permitiu, aos alunos, um modo generalizado de ação na busca da solução do problema. A produção do texto traz implícita a sequência das operações necessárias à ação. "Quando o ensino traz a reflexão como elemento básico, não se ocupa apenas de transmissão de conteúdo, mas também de método para a aquisição de conhecimentos" (SFORNI, 2004, p. 136). A possibilidade de rever e reestruturar a montagem da caixinha somente foi possível em razão das condições ofertadas: organização do trabalho em sala de aula e a cons- 
trução coletiva do texto por meio da ação dirigida pela professora. Na discussão, foi possível valorizar as diferentes soluções apresentadas e acompanhar a organização do pensamento em torno da ação.

Quando a ação da equipe estava voltada apenas para aspectos externos da caixa, os elementos de generalização não tinham sido percebidos pelas crianças. A promoção do diálogo coletivo permitiu uma direção à atenção do aluno, contribuindo para o processo de reflexão que reorienta as ações individuais e coletivas. O processo de análise depende da reflexão.

As crianças não gostam de escrever matemática. Matemática, para elas, é calcular, saber tabuada e resolver situações-problema já conhecidas. Entretanto, a necessidade de construir a caixinha promoveu esta ação. Seguindo as sugestões do texto, montaram, individualmente, as caixas usando papel de bobina para embrulho. Observamos que, muitas dessas crianças, nunca tinham construído uma caixinha.

\section{Criança LO: - "Professora, eu posso levar a minha caixinha para casa?" \\ Pesq.: - "Quem quiser, pode levar a caixinha para casa."}

A fala da criança LO revela que, quando a aprendizagem se transforma em uma atividade para a criança, ela não se atém somente ao aspecto cognitivo, mas mobiliza aspectos afetivos, emocionais, extrapolando o espaço da sala de aula.

No encontro seguinte, cada equipe construiu, sem dificuldades, a caixinha em cartolina, para guardar o Jogo de Memória, patrimônio que passou a pertencer à turma. Descobriram quantas peças podiam ser armazenadas naquela caixa, ou seja, a capacidade da caixinha, seu volume. As relações que as crianças conseguiram estabelecer entre o número de peças em cada camada e o número de camadas utilizadas, assim como a caixa mais adequada para guardar o jogo, produziram elementos para a compreensão do conceito de volume.

\section{Criança LO: - "Professora, en fiz muitas caixinhas em casa, agora eu sei fažer."}

A resolução do problema não exigiu apenas a construção da caixa mais adequada, mas a consciência do que move a ação, a compreensão dos critérios e dos conhecimentos essenciais para estabelecer esses critérios. A criança LO, a sua maneira, expõe a importância de ter adquirido um modo de ação geral que serviu como referência na construção de outras caixas. À medida que a criança se utiliza dos conceitos geométricos como instrumentos orientadores para solucionar situações desafiadoras, mobiliza processos de reflexão, análise e síntese. Assim, deixa de agir por tentativa e erro e passa a planejar suas ações com base no conhecimento adquirido. Essa apropriação manifesta-se na modificação do seu modo de realização da ação, daí por que o seu modo de atuar expressa um novo modo de pensar, constituindo um elemento revelador de seu desenvolvimento psíquico. 


\section{Considerações finais}

De maneira geral, as práticas pedagógicas têm revelado que o ensino de Geometria, nas séries iniciais do Ensino Fundamental, tem se resumido à identificação de formas geométricas, e, nas séries posteriores, às regras, às fórmulas e aos cálculos. O tratamento que tem sido dado ao ensino de volume não se diferencia daquele que ocorre com os demais conceitos, ou seja, está baseado na memorização, utilização e aplicação de fórmulas.

Entendemos, porém, que as ações educativas organizadas na escola podem possibilitar que o sujeito, cada vez mais, se aproprie do conhecimento científico, para que possa intervir de forma objetiva no seu meio físico e social.

Observamos que a aprendizagem escolar é promotora de desenvolvimento, mas somente sob certas condições. Se considerarmos que essa aprendizagem não é de natureza perceptual, mas de natureza conceitual, a prática pedagógica é modificada. No primeiro caso, o ensino centra-se em manipulação de objetos e repetição de procedimentos. No segundo caso, exige-se a organização de situações de ensino em que as ações dos estudantes são mediadas pela matemática. Nesse processo, a mediação do professor ocorre no sentido de promover a reflexão e análise dos alunos em torno das ações realizadas e daquelas que poderiam ser realizadas, nas quais os conceitos matemáticos estão implícitos e que, na interação entre aluno-aluno e alunos-professor, devem se tornar explícitos.

Isso significa que as funções psíquicas superiores são mobilizadas na resolução das atividades realizadas, estando aí, a, possibilidade de o ensino ser promotor do desenvolvimento dos estudantes. Para isso é fundamental que as atividades de ensino sejam organizadas levando em consideração essa possibilidade formativa nos conceitos científicos.

Ao tomarmos, como referência, a Teoria da Atividade de Leontiev (1998), assumimos que o educando somente entra em atividade de aprendizagem quando necessidades e motivos de aprender o conceito são desencadeados pela atividade do professor. Nesse sentido, se o nomear figuras e o identificar fórmulas para cálculos não estiverem inseridos em uma atividade cujo significado como ferramenta simbólica esteja explícito, podemos considerar que há ensino de Geometria na escola, mas não, efetivamente, aprendizagem de um pensamento geométrico.

A metodologia de natureza qualitativa e de intervenção possibilitou o acompanhamento das ações das crianças na elaboração de soluções para as situações propostas. É, na troca com o professor e com os seus pares, que os sujeitos vão internalizando conhecimentos, papéis e funções sociais, o que possibilita o desenvolvimento do conhecimento e da consciência. Esse movimento de formação caminha do plano social, das relações interpsíquicas, para o plano individual, para as relações intrapsíquicas.

Compreendíamos o pressuposto de Leontiev (1998) de que o determinante no desenvolvimento do psiquismo da criança é a evolução de sua atividade, tanto interna como externa. Mas reconhecíamos a dificuldade de analisar se houve ou não modificação da atividade interna dos alunos a partir das situações de ensino. A modificação das funções psíquicas, promovida pela internalização, é um processo interno do sujeito, difícil de ser observado, mas, na linguagem e nas ações externas manifestadas pelos alunos, é possível constatarmos evidências da qualidade da aprendizagem que está ocorrendo. Quando o estudante explica por que resolveu um problema de uma determinada forma, percebemos se ele está utilizando um conheci- 
mento conceitual ou apenas perceptual, preso a situação empírica, ou ainda, apenas repetindo mecanicamente procedimentos aprendidos em outras situações. Quando lida com os objetos concretos, percebemos se age por tentativa e erro ou se orientado por algum princípio decorrente de um conhecimento conceitual. Quando escreve as conclusões nas atividades, identificamos a percepção dos elementos de generalização decorrentes da tomada de consciência. Enfim, uma série de falas e ações nos dão pistas sobre a qualidade da aprendizagem ocorrida. É fundamental que o professor considere a elaboração da atividade de ensino como uma necessidade na sua forma de agir intencionalmente. Assim, colocar-se-á como sujeito ativo no processo de ensino e aprendizagem.

Consideramos que houve uma nova relação do sujeito com o objeto da aprendizagem. As atividades de ensino organizadas e desenvolvidas nos permitiram observar que as ações das crianças são reveladoras do seu desenvolvimento psíquico, na medida em que essas evidenciam a utilização dos conceitos geométricos como instrumentos orientadores na busca de soluções diante de situações desafiadoras, conferindo-lhe aspectos sempre mais generalizáveis. As crianças que, inicialmente, agiam por tentativas e erros ou repetição de procedimentos sem compreensão, reelaboraram seus conhecimentos, e suas ações passaram a ser permeadas pela reflexão e análise.

Todavia, não podemos afirmar que esse desenvolvimento tenha alcançado o mesmo nível em cada criança. Isso porque, como afirma Kostiuk (1997), o desenvolvimento psíquico não é uma simples réplica das influências educativas a que a criança esta sujeita - há uma seleção, uma transformação interna, uma reorganização, uma interação com o objeto do conhecimento, o que, certamente, não se processa de modo idêntico e ao mesmo tempo em todos os sujeitos.

\section{Referências}

BRASIL. Ministério da Educação. Instituto Nacional de Estudos e Pesquisas Educacionais. Exame Nacional do Ensino Médio. Brasília: INEP, 2010.

. Ministério da Educação. Instituto Nacional de Estudos e Pesquisas Educacionais. Exame Nacional do Ensino Médio. Brasília: INEP, 2009a.

Ministério da Educação. Instituto Nacional de Estudos e Pesquisas Educacionais. Prova Brasil. Brasília: INEP, 2009b.

. Ministério da Educação. Instituto Nacional de Estudos e Pesquisas Educacionais. Prova Brasil. Brasília: INEP, 2007.

DAVYDOV, V. V. La ensenãnza escolar y el desarollo psiquico: investigación psicologica teórica y experimental. Moscou: Editorial Progreso, 1988.

FIORENTINI, D.; MIORIM, M. A. Uma reflexão sobre o uso de materiais concretos e jogos no ensino da matemática. Boletim SBEM, São Paulo, v. 4, n. 7, 1993. 
Rodrigues, V. L. G. C.; Sforni, M. S. F.

KOSTIUK, G. S. Alguns aspectos da relação recíproca entre educação e desenvolvimento da personalidade. In: LURIA, A. R.; LEONTIEV, A. N.; VYGOTSKY, L. S. (Orgs.).

Pensamento e linguagem: as últimas conferências de Luria. Porto Alegre: Artes Médicas, 1997. p. 19-36.

LEONTIEV, A. N. Uma contribuição à teoria do desenvolvimento da psiqué infantil. In: VYGOTSKY, L. S.; LURIA, A. R.; LEONTIEV, A. N. (Orgs.). Linguagem, desenvolvimento e aprendizagem. São Paulo: Ícone, 1998. p. 59-83.

LIBÂNEO, J. C. Didática e trabalho docente: como melhorar as aulas visando a aprendizagem dos alunos e a formação da personalidade. Disponível em: <http:/ / educacaoinfantilead.blogspot.com/2009/09/lev-semenovich-vygotsky.html>. Acesso em: 12 jun. 2010.

LIMA, L. C.; MOISÉS, R. P. A fração: a repartição da terra. São Paulo: CEVEC-CIARTE, 1998.

LORENZATO, S. Por que não ensinar geometria? Educação Matemática em Revista Revista da Sociedade Brasileira de Educação Matemática, n. 4, p. 3-13, 1995.

MOURA, M. O. A atividade de ensino como ação formadora. In: CASTRO, A.; CARVAlHO, A. (Orgs.). Ensinar a ensinar: didática para a escola. São Paulo: Pioneira, 2001. p. 143-162.

Construção do signo numérico em situação de ensino. 1992. 151f. Tese

(Doutorado em Educação) - Faculdade de Educação, Universidade de São Paulo, São Paulo, 1992.

PASSOS, C. L. B. Representações, interpretações e prática pedagógica: a geometria na sala de aula. 2000. 348f. Tese (Doutorado em Educação) - Faculdade de Educação, Universidade Estadual de Campinas, Campinas, 2000.

PAVANELLO, R. M. O abandono de ensino de geometria: uma visão histórica. 1989. 196f. Dissertação (Mestrado em Educação) - Faculdade de Educação, Universidade Estadual de Campinas, Campinas, 1989.

RODRIGUES, V. L. G. C. Aprendizagem do conceito de volume e o desenvolvimento intelectual: uma experiência no Ensino Fundamental. 2006. 167f. Dissertação (Mestrado em Educação) - Universidade Estadual de Maringá, Maringá, 2006. Disponível em: <http:/ /www.ppe.uem.br/dissertacoes/2006-Vera_Rodrigues.pdf>. Acesso em: 12 jun. 2010.

SFORNI, M. S. F. Aprendizagem conceitual e organização do ensino: contribuições da teoria da atividade. Araraquara: JM Editora, 2004.

VYGOTSKY, L. S. A formação social da mente: desenvolvimento dos processos psicológicos superiores. São Paulo: Martins Fontes, 1984.

. Psicologia pedagógica. São Paulo: Martins Fontes, 2001.

Artigo recebido em setembro de 2009 e aceito em julho de 2010. 